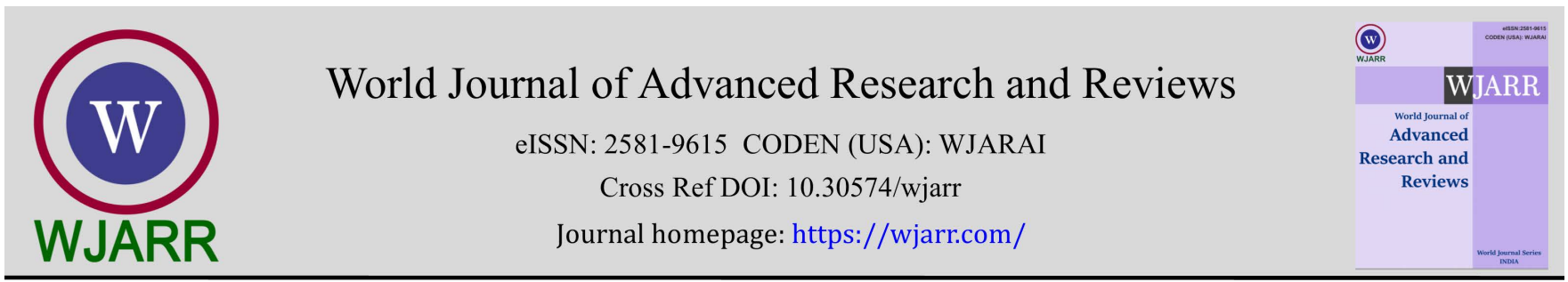

(RESEARCH ARTiCle)

Check for updates

\title{
Hydrocephalus Surgery in Touba City (Senegal): 0\% infection Preliminary study about 20 cases
}

Wague Daouda $1,{ }^{*}$, CISSE Mouhamet Abdoulaye ${ }^{2}$, Sarr Ndeye Ndoumbe 2, Thioub Mbaye 3 , Mbaye Maguette 3, Gaye Maguatte ${ }^{4}$ and Thiam Alioune Badara ${ }^{3}$

\footnotetext{
${ }^{1}$ Neurosurgeon at Centre Hospitalier Matlaboulfawzaini of Touba/Diourbel-Senegal

2 Neurosurgery Resident at CHU (Centre Hospitalier Universitaire de Fann)/Dakar-Senegal.

${ }^{3}$ Neurosurgeon at CHU Fann and Professor of neurosurgery at UCAD (Université Cheikh Anta Diop de Dakar)/DakarSenegal.

${ }^{4}$ Head Master of Neurosurgery at HOGIP (Hopital General Idrissa Pouye) and Professor of neurosurgery at UCAD.
}

World Journal of Advanced Research and Reviews, 2021, 12(02), 315-323

Publication history: Received on 10 October 2021; revised on 13 November 2021; accepted on 15 November 2021

Article DOI: https://doi.org/10.30574/wjarr.2021.12.2.0603

\begin{abstract}
Introduction: Infection is the most common complication encountered after ventriculoperitoneal shunt.
\end{abstract}

The AIMS of this study is to evaluate the effectiveness of antibiotic therapy with protocol in the prevention of postoperative infections after ventriculoperitoneal shunt in our city.

Patients and methods: We retrospectively study 20 hydrocephalus cases in one year. They were operated through the classic VP Shunt insertion technique and with the protocol adopted for shunt implantation. They received antibiotic therapy for ten days.

Results: In one year we operated 95 patients,20 (21\%) cases were hydrocephalus.

There were 7 males et 13 females (ratio:0,53). The age of patients ranged from 15 days to 12 years and the average age was 13,5 months. The average consultation time was 5,6 weeks. Clinically the most common sign were anterior fontanelle tense $(100 \%)$, macrocrania $(60 \%)$,vomiting $(80 \%)$ and sunset eye sign $(80 \%)$.

Brain CT-scan was performed in all patient, $66 \%$ of patients had Transfontanelle Ultrasonography and anyone hadn't performed MRI.

All cases underwent surgical treatment. only ventriculoperitoneal shunt was performed and the standard technique protocol to minimize infection was done during surgery. All of them received ceftriaxone $100 \mathrm{mg} / \mathrm{kg} / \mathrm{day}$ for five days then oral relay by thiamphenicol $50 \mathrm{mg} / \mathrm{Kg} /$ day for five days.

The follow up was good no infection was found $(0 \%)$.

Conclusion: Establishing an aseptic protocol for the shunt is essential to reduce the rate of postoperative infections. This result becomes better when we make a combination of antibiotic therapy and protocol. We can achieve infection rates to zero or less than $1 \%$ in case of association

Keywords: Hydrocephalus; Shunt; Infection; Antibiotic

\footnotetext{
* Corresponding author: Wague Daouda

Neurosurgeon at Centre Hospitalier Matlaboulfawzaini of Touba/Diourbel-Senegal.

Copyright (C) 2021 Author (s) retain the copyright of this article. This article is published under the terms of the Creative Commons Attribution Liscense 4.0.
} 


\section{Introduction}

For a century since the first cerebrospinal fluid (CSF) shunt surgery, ventriculoperitoneal (VP) shunt insertion for the treatment of hydrocephalus has routinely been performed [1].

It can lead to improvement in the quality of life. However, the gains in the quality of life after shunting are often subdued by significant failure rates from complications like malfunction and shunt infection. Mortality rates are still elevated ranging from 10 to $15 \%$. Established protocols have contributed to the reduction of ventriculoperitoneal shunt (VPS) infections $[2,3]$.

The AIMS of this study is to evaluate the effectiveness of antibiotic therapy with protocol in the prevention of postoperative infections after ventriculoperitoneal shunt in our city.

\section{Patients and Methods}

We did retrospective study in one year (August2020 to August 2021) at Matlaboulfawzaini hospital in Touba. This study is based on 20 children.

We included all children who had hydrocephalus surgery in our hospital.

We excluded hydrocephalus in adults.

Patients with hydrocephalus indicated for shunting were booked for surgery after anesthetic clearance. They were operated through the classic VP Shunt insertion technique and with the protocol adopted for shunt implantation is as in Table 1.They received antibiotic therapy for ten days.

Follow-up was from the time of admission for shunt insertion to 6 months after the shunting operation.

\subsection{Statistical Analysis}

Analysis was done using Microsoft office excel 2016

\subsection{Protocol to minimize infection}

Standard technic before and during surgery (table 1)

Using of antibiotic after surgery:

C3G antibiotic like ceftriaxone $100 \mathrm{mg} / \mathrm{Kg}$ /days was use for five days then oral relay with phenicols antibiotic like thiamphenicol $50 \mathrm{mg} / \mathrm{kg} /$ days for five days.

Table 1 Protocol to minimize infection

Protocol to minimize infection: standard technique
- Shunts done in the morning
- Patients were shaved with razor on the theater operating table
- Patients chest, abdomen, and shaved scalp area then thoroughly washed
- Prophylactic antibiotic given at induction of anesthesia
- Avoid to touch shunt hardware with gloves :use dissecting forceps
- A small burr hole allowing entry of the catheter to avoid the leak of CSF
- (Figure1)
change of gloves prior to handling shunt hardware




\section{Results}

In one year we operated 95 patients,20 (21\%) cases were hydrocephalus.

There were 7 males et 13 females (ratio:0,53) . the age of patients ranged from 15 days to 12 years and the average age was 13,5 months. The average consultation time was 5,6 week. Clinicaly the most common sign were anterior fontanelle tense $(100 \%)$, macrocrania (60\%), vomiting (80\%) and sunset eye sign (80\%) table2,figure 2.

The anterior fontanelle bulging and slightly depressible in 8 (40\%) cases and bulging not depressible in 12 (60\%) cases.

Table 2 Clinical results of hydrocephalus symptoms and signs

\begin{tabular}{|l|c|}
\hline \multicolumn{1}{|c|}{ Signs } & Number of Cases (\%) \\
\hline Macrocrania & $12(60)$ \\
\hline blindness & $03(15)$ \\
\hline vomiting & $16(80)$ \\
\hline Retarded psychomotor development & $05(25)$ \\
\hline Anterior fontanelle bulging & $20(100)$ \\
\hline nutrition & $04(20)$ \\
\hline Spina bifida & $05(25)$ \\
\hline Fundus oculi & $02(10)$ \\
\hline Sunset eye sign & $16(80)$ \\
\hline
\end{tabular}

Head circumference (WHO infant head circumference for age percentiles) was measured in all children and we had macrocephaly in 12 cases $(60 \%)$.

During the study 2 children had big macrocephaly, greater than two times normal.

Brain CT-scan was performed in all patient,66\% of patient had Transfontanelle Ultrasonography and anyone hadn't perform MRI. Figure 3 et 4

Hydrocephalus causes were :meningitis in 03 cases (15\%), malformative in 16 cases (80\%) and posterior fossa tumor in 1 case $(5 \%)$.

Congenital or malformative hydrocephalus were 16: aqueductal stenosis 08 (40\%), dandy walker cyst 05 (25\%) ,hydranencephaly 02 (10\%) and schizencephalia 01 (5\%) .

All cases underwent surgical treatment. only ventricul operitoneal shunt was performed. In Touba city the Chabbra surgywear valve system is used. The average surgical time between consultation and surgery was 3,15 weeks.

Two children who had hydrocephalia with spina bifida: surgery was done in the same operating time. We began by Ventriculoperitoneal shunt and after we return the child and perform spina bifida cure. Figure 5

All of them received ceftriaxone $100 \mathrm{mg} / \mathrm{kg}$ /day for five days then oral relay by thiamphenicol $50 \mathrm{mg} / \mathrm{Kg} / \mathrm{day}$ for five days.

The follow up was good no infection was found.

During the study 3 patients had complications the first was migration of ventriculoperitoneal shunt through the anus ,in fact the distal part of the peritoneal catheter protruding from the anus. there were no clinical features of peritonitis then we removed the shunt catheter. The second complication was abdominal bloating and the last was limited proximal 
catheter in the ventricle. These last two showed good progress under treatment, one received laxatives to regress the bloating and the other had a revised shunt.

Three patients who had blindness, one had regained sight one month after surgery.

she was a girl who had tuberculous meningitis complicated by hydrocephalus with signs of ICP (Increased Intracranial Pressure) and bilateral blindness evolving since 03months. After the surgery she regained her vision two weeks later with visual acuity at 6/10 on the right and 5/10 on the left eyes.

Brain CT scan control was performed in $8(40 \%)$ cases.

We followed and saw children on consultation one month after surgery then three month, also 6 month and one year. Figure 6

Table 3 Results of psychomotor development follow-up after surgery at 3 months and 6 months

\begin{tabular}{|l|c|c|}
\hline Psychomotor developpement & Months after surgery & Cas (\%) \\
\hline Head control & 3 & $11(61)$ \\
\hline Head control & 6 & $15(83)$ \\
\hline Sit up & 6 & $09(45)$ \\
\hline
\end{tabular}

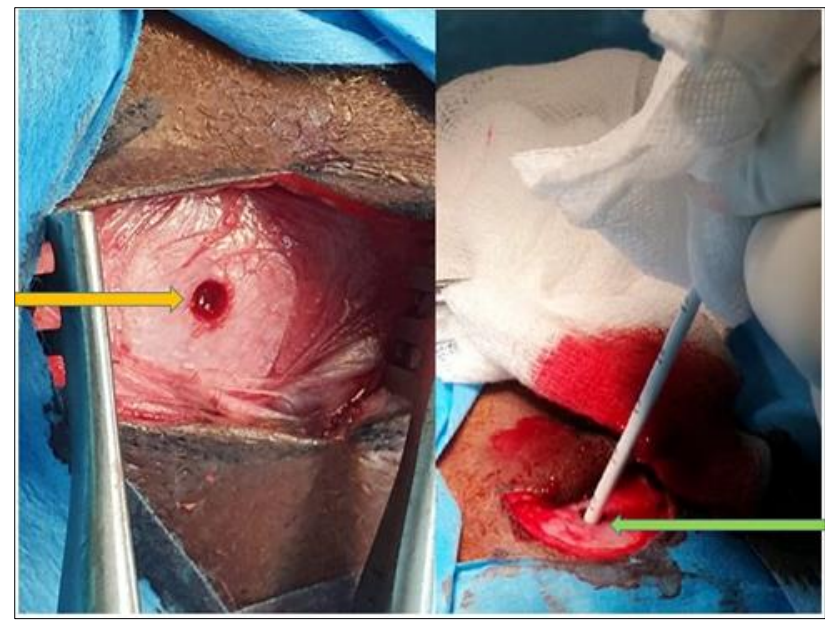

Figure 1 Small burr hole showed by yellow arrow

In green arrow the burr hole allowing only the entry of catheter:a limit hole For the catheter.

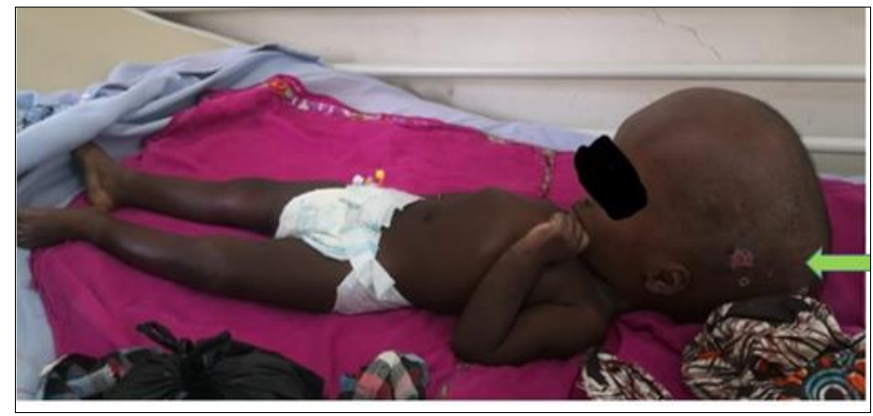

Figure 2 Macrocrania in green arrow head circumference measured at $60 \mathrm{~cm}$ in 02 month old infant 


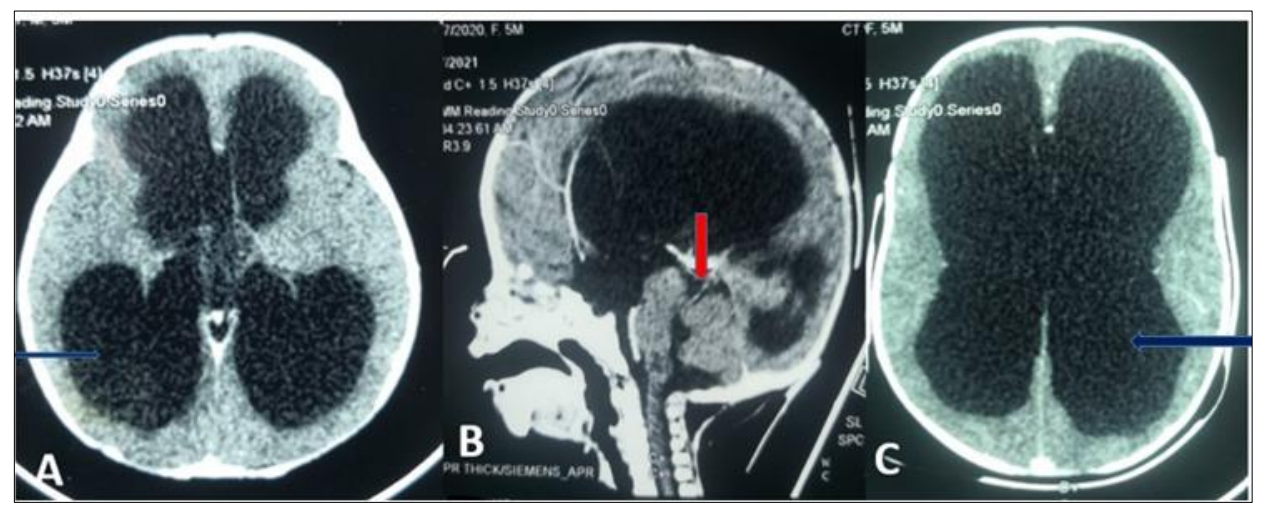

Figure 3 Brain CT-scan showed hydrocephalus; A and C: enlargement of the ventricles in blue arrow; B: Aqueductal stenosis in red arrow

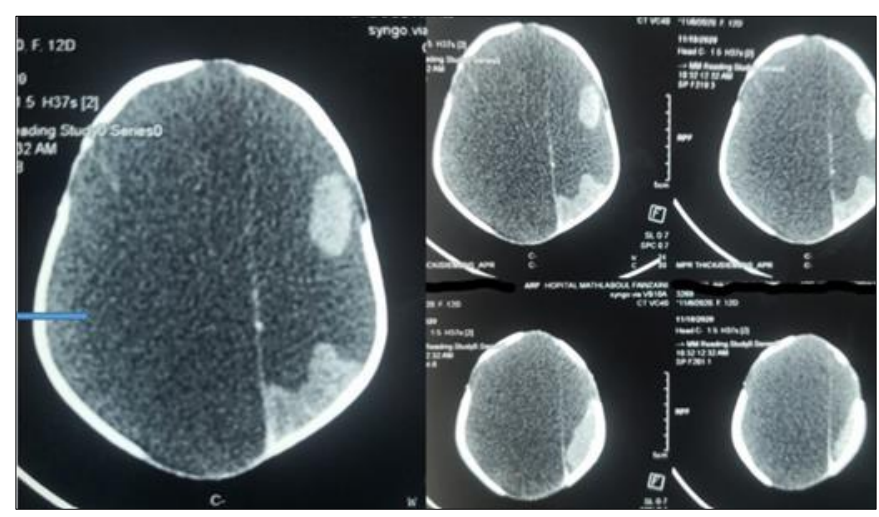

Figure 4 Brain CT-scan :showed congenital hydrocephalus Large dilatation of ventricles in blue arrow with absent septum pellucidum and callosal hypogenesis

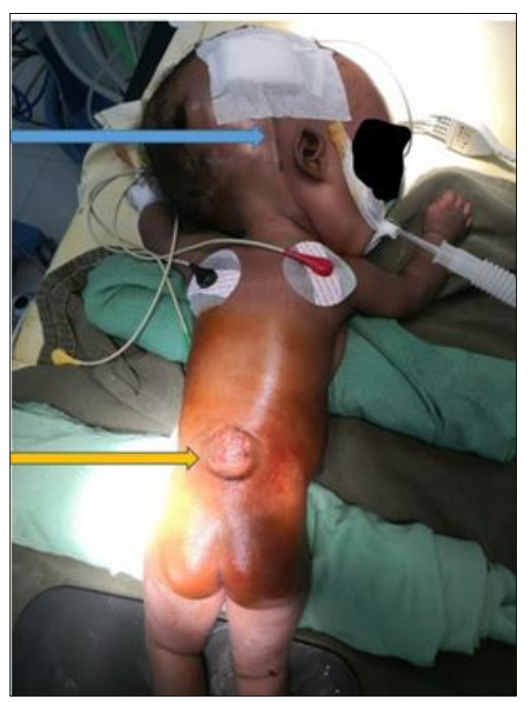

Figure 5 Shunt and spina bifida performed in the same surgery In blue arrow showed reservoir of shunt In yellow arrow infant was turned for spina bifida cure 


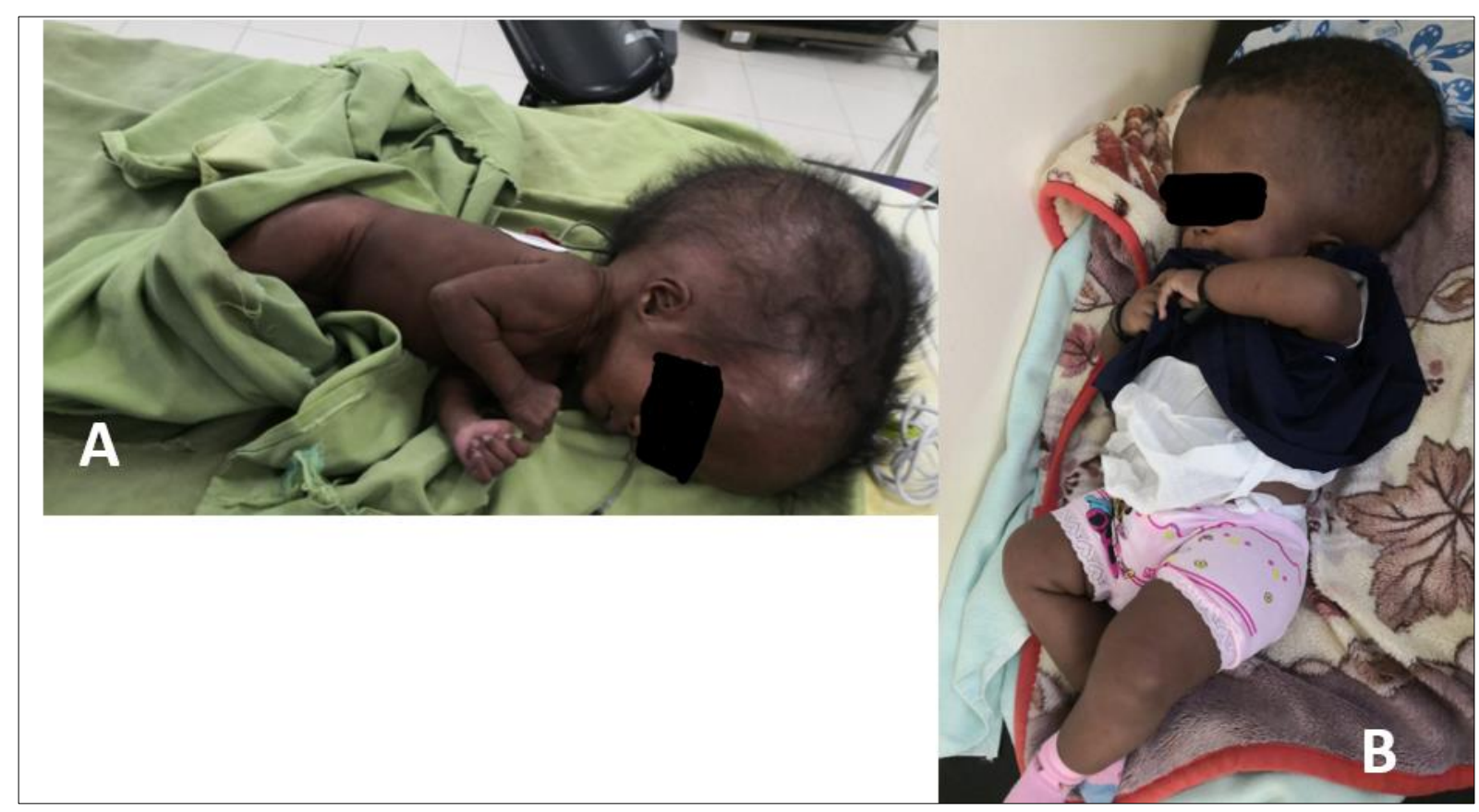

Figure 6 Infant follow up with big macrocrania; A: When he was 01 month old the days of surgery; B:When he was 6 months old after shunt

\section{Discussion}

Hydrocephalus is a common neurosurgical problem in the pediatric age group [4].over one year 21\% of our patient who operated in neurosurgery were hydrocephalus. In fact Neurosurgery didn't exist in this city before July 2020 . We are the first who started neurosurgery in this hospital.

The average consultation time was 5,6 week. This delay is explained by: in certain remote areas, some women don't do antenatal consultation ,also the lack of pre and post-natal hydrocephalus diagnostic such as ultrasound which doesn't exist in these areas. The assimilation of hydrocephalus to mysterious disease is one cause of diagnostic delay in our city. The care of hydrocephalus in sub-Saharan Africa is hampered by economic constraints (poverty), difficulties for patients and families in securing transportation means and access to adequate care, and cultural mistakes/ misunderstandings related to hydrocephalus $[5,6]$.

Macrocrania was found in $60 \%$ of cases due to delayed diagnosis. In northern Mozambique Salvador et al found macrocrania in all children [5].

Most infants presented congenital hydrocephalus (80\%). This diagnostic was confirmed only with the use of cranioencephalic CT, since there is no magnetic resonance image (MRI) apparatus at Touba Hospital.

In Africa, post-infectious etiology varies from 7\% [7,8] to 60\%, [9] and is correlated to the level of health of the considered population [7]. During the study we found 15\% hydrocephalus post meningitis ,in the same country at Fann Hospital in Dakar our capital city, Ba et al found 45\% hydrocephalus post meningitis in 2008. This predominance of post-infectious hydrocephalus has started to diminish, thanks to the effectiveness of prevention, in particular expanded vaccination programs which are systematic and which currently affect a large part of the population (More than $77 \%$ in Dakar according to the Ministry of Health) [7].

Although the methods of choice for the study of hydrocephalus are MRI and CT, $[10,11,12]$ the transfontanellar ultrasound plays an important role in the diagnosis and characterization of brain lesions in the newborn (hemorrhage, ventricular dilatation, malformations, etc.) for its safety and ease of implementation, for the possibility of serial exams to assess the evolution of brain lesions and for having hydrocephalus diagnosis early, transfontanellar ultrasound is considered a method of choice in the evaluation of the newborn at risk [5,13].66\% of our patient had Transfontanelle Ultrasonography, it should be more used, it is painless, relative easy to perform, more readily available than MRI and 
CT, and provides valuable clinical information. Capacitating senegalese health care workers in remote area to perform this type of ultrasound examination is necessary.

Among VPS complications, infection continues to be a serious cause of shunt failure; is the major source of morbimortality, an important contributor to the cost of care and a true frustrating problem for clinicians [14]. Several protocols have been developed and implemented over the years to curb shunt infection $[15,16,17,18,19$,] but only very few centers in the world have achieved infection rate below 1\% [20].

Motelese et al reported 2,8\% infection rate, Choux et al 0,17\%,Kazadi et al 1,9\%,Pirotte et al <1\% [18,15,2,21].

These centers employ precautions that are difficult to replicate in our hospital. We are in a city without sanitation so there are too many insects like flies. Usually there are flies in the operating room despite the effort of regular use of insecticides and others methods in the wards.

Elsewhere, the staff in the operating room are not trained to work with neurosurgeons. Less than a year before our arrival, neurosurgery never existed in this region.

Considering all these factors and the rate of infection linked to the shunts pushed us to establish our protocol for shunt, but above all to insist on antibiotic therapy with C3G at least for 05 days then oral relay with phenicols for five days. In our series we had $0 \%$ infection.

$5(25 \%)$ children had spina bifida with hydrocephalus in this serie. At the beginning when we started the surgery we first did the spina cure and we waited two weeks after that the wound was completely healed and that there was no infection to perform the shunt. After 6 months when we saw that the protocol to minimize infection was good $(0 \%$ infection), we started to perform shunt and cure spina bifida at the same time surgery. The same protocol was perform and no infection was found.

we knew that we have to fear antibiotic resistance, if we assess the balance benefit/risk. We think that it's more beneficial to use antibiotic in this context because our operating rooms do not meet the recommended asepsis rules. In case of meningitis the duration of the treatment is longer and some patients in rural areas had economics constraints, they cannot buy the antibiotics correctly during the whole treatment of meningitis; they start at the beginning and thereafter can no longer buy the antibiotics. In addition when there is meningitis we remove the shunt, then treat infection, after the patient repay a new ventriculoperitoneal shunt catheter for surgery which is not free either and finally the morbidity associated with meningitis too. Faced with all the elements mentioned above, we think that 05 days of injectable antibiotics then 05 days of oral relay to reach $0 \%$ infection or decrease the infection rate is justified in this context. However to avoid antibiotic resistance we will limit this study to these 20 cases and we will use prophylactic antibiotic and the protocols to minimize infection then we will compare them with these results.

During the study we had one patient who the distal part of the peritoneal catheter protruding from the anus .This complication presumed to be due to intestinal peristalsis which may pull down the shunt. Others possible factors suggested that may predispose to this complication of ventriculoperitoneal shunting include a weak bowel musculature in myelomeningocele, the use of stiff peritoneal catheters and local infective adhesions $[22,23,24]$. The mechanism of anal extrusion is uncertain and it possibly occurs when a long tubing is left in the abdominal cavity. The perforation of the bowel lumen occurs when the freely moving catheter gets adherent to the serosa of a viscus and the bevelled end of the tube, coupled with the continuous water hammer effect of the cerebrospinal fluid pulsations, penetrate the walls and eventually perforate the viscus. Thereafter the peristaltic waves drive the 'foreign body' forward [25].

\section{Conclusion}

Post-operative infection after shunt remains a problem in sub-Saharan Africa.

Establishing an aseptic protocol for the shunt is essential to reduce the rate of postoperative infections. This result becomes better when we make a combination of antibiotic therapy and protocol. We can achieve infection rates to zero or less than $1 \%$ in case of association. 


\section{Compliance with ethical standards}

\section{Acknowledgments}

Acknowledgments to all neurosurgeons who participated in this study. We thank our masters of Senegal who trained us, the staff of Touba hospital and WJARR who agreed to publish this article

\section{Disclosure of conflict of interest}

There is no conflict of interest in this study.

\section{Statement of informed consent}

Informed consent was obtained from all individual participants included in the study.

\section{Abbreviations}

CT-scan: computer tomography

MRI: Magnetic Resonance Imagerie

VPS: Ventriculoperitoneal shunt

ICP: Increased Intracranial Pressure

CSF: Cerebrospinal Fluid

VP shunt: Ventriculo Peritoneal Shunt

\section{References}

[1] Edward O. Komolafea Augustine A. Adeolua Morenikeji A. Komolafeb Treatment of Cerebrospinal Fluid Shunting Complications in a Nigerian Neurosurgery Programme Pediatr Neurosurg. 2008; 44: 36-42.

[2] Kazadi KN, Kalangu Ignatius N, Esene. aximillian Dzowa Towards zero infection for ventriculoperitoneal shunt insertion in resource-limited settings: a multicenter prospective cohort study Child's Nervous System .2020 Feb;36(2):401-409. doi: 10.1007/s00381-019-04357-z. Epub 2019 Aug 27.

[3] Greenberg MS. Ch. 21:Skull, spine, and post-surgical infections: 21.1 shunt infection. In: Greenberg MS (ed) Handbook of neurosurgery. Thieme, New York. 2016; 339-342.

[4] Kalangu KK. (2000) Pediatric neurosurgery in Africa-present and future. Childs Nerv Syst. 2000; 16: 770-775.

[5] Sérgio F. Salvador, João Carlos Henriques, Missael Munguambe, Rui M. C. Vaz, Henrique P. Barros Hydrocephalus in children less than 1 year of age in northern Mozambique Surgical Neurology International .2014; 5: 175.

[6] Kulkarni AV, Warf BC, Drake JM, Mallucci CL, Sgouros S, Constantini S. Canadian Pediatric Neurosurgery Study Group. Surgery for hydrocephalus in sub-Saharan Africa versus developed nations: A risk-adjusted comparison of outcome. Childs Nerv Syst. 2010; 26: 1711-7.

[7] Ba MC, Kpelao ES, Thioub M, Kouara M, Thiam AB, Ndoye N, et al. Hydrocéphalie post-méningitique chez les nourrissons à Dakar (Post meningitis hydrocephalus in the infants in Dakar) . Afr J Neurol Sci. 2012; 31: 8-15.

[8] PeacockWJ, Currer TH. Hydrocephalus in childhood. A study of 440 cases. S Afr Med J. 1984; 66: 323-4.

[9] Warf BC. Hydrocephalus in Uganda: The predominance of infectious origin and primary management with endoscopic third ventriculostomy. J Neurosurg. 2005; 102 (1 Suppl) : S1-15.

[10] Dincer A, Ozek MM. Radiologic evaluation of pediatric hydrocephalus. Childs Nerv Syst. 2011; 27: $1543-62$.

[11] O'Neill BR, Pruthi S, Bains H, Robison R, Weir K, Ojemann J, et al. Rapid sequence magnetic resonance imaging in the assessment of children with hydrocephalus. World Neurosurg. 2013; 80: e307-12.

[12] Pomschar A, Koerte I, Peraud A, Heinen F, Herber-Jonat S, Reiser M, et al. Hydrocephalus in childhood: Causes and imaging patterns. Radiologe. 2012; 52: 813-2.

[13] Dewbury KC, Bates RI. The value of transfontanellar ultrasound in infants. Br J Radiol. 1981; 54: 1044-52.

[14] Akhaddar A. Complications of extrathecal CSF shunts:infective complications. In: Di Rocco C, Turgut M, Jallo G, MartínezLage JF (eds) Complications of CSF shunting in hydrocephalus: prevention, identification, and management. Springer International Publishing, Cham. 2015; 141-149. 
[15] Choux M, Genitori L, Lang D, Lena G. Shunt implantation: reducing the incidence of shunt infection. J Neurosurg. 1992; 77: 875-880.

[16] Kestle JR, Hoffman HJ, Soloniuk D, Humphreys RP, Drake JM, Hendrick EB. A concerted effort to prevent shunt infection. Childs Nerv Syst. 1993; 9: 163-165.

[17] Kestle JR, Riva-Cambrin J, Wellons JC III, Kulkarni AV, Whitehead WE, Walker ML, Oakes WJ, Drake JM, Luerssen TG, Simon TD, Holubkov R. A standardized protocol to reduce cerebrospinal fluid shunt infection: the Hydrocephalus Clinical Research Network Quality Improvement Initiative. J Neurosurg Pediatr. 2011; 8: 22-29.

[18] Mottolese C, Grando J, Convert J, Abdoulrahman M, Lelievre H, Vandenesch F, Bret P, Lapras C. Zero rate of shunt infection in the first postoperative year in children-dream or reality? Childs Nerv Syst. 2000; 16: 210-212.

[19] Musara A, Kalangu K. Ventriculperitoneal shunt infection in pediatric age group in Harare, Zimbabwe. Childs Nerv Syst. 2008; 24: 1280.

[20] Sarmey N, Kshettry VR, Shriver MF, Habboub G, Machado AG, Weil RJ. Evidence-based interventions to reduce shunt infections: a systematic review. Childs Nerv Syst. 2015; 31: 541-549.

[21] Pirotte BJ, Lubansu A, Bruneau M, Loqa C, Van CN, Brotchi J. Sterile surgical technique for shunt placement reduces the shunt infection rate in children: preliminary analysis of a prospective protocol in 115 consecutive procedures. Childs Nerv Syst. 2007; 23: 1251-1261.

[22] Adeloye A. Protrusion du shunt ventriculo-péritonéal par l'anus : à propos de deux cas. Afrique de l'Est Med J. 1997; $74:$ 337-339.

[23] Miserocchi G, Sironi VA, Ravagnati L. La protrusion anale en tant que complication du shunt ventriculopéritonéal. Rapport de cas et revue de la littérature.J Neurosurg Sci. 1984; 28: 43-46.

[24] Digray NC, Thappa DR, Arora M, Mengi Y, Goswamy HL. Perforation intestinale silencieuse et prolapsus transanal d'un shunt ventriculopéritonéal. Pédiatre Chirurgie Int. 2000; 16: 94-95.

[25] R Handa, Retd,R Kale, MM Harjai. Unusual Complication of Ventriculoperitoneal Shunt: Anal Extrusion Med J Armed Forces India. 2007 Jan; 63 (1) : 82-84.

\section{Author's short biography}

I'm Dr WAGUE Daouda young neurosurgeon in touba city in west of Africa in Senegal.
I am the only neurosurgeon in this city for a population more than a million without counting
the other people who come from others regions.Our big problem we encounter is the lack of
equipment but we try to work and do neurosurgery in the best way. We publish our results
to show the world how we work in rural area.

